\title{
The Incidence and Risk Factors for Metachronous Gastric Cancer in the Remnant Stomach after Gastric Cancer Surgery
}

\author{
Yonghoon Choi ${ }^{1}$, Nayoung Kim ${ }^{1,2}$, Hyuk Yoon ${ }^{1}$, Cheol Min Shin ${ }^{1}$, Young Soo Park' ${ }^{1}$, Dong Ho Lee ${ }^{1,2}$, Young Suk \\ Park ${ }^{3}$, Sang-Hoon Ahn ${ }^{3}$, Yun-Suhk Suh ${ }^{3}$, Do Joong Park ${ }^{4}$, and Hyung Ho Kim ${ }^{3,4}$ \\ ${ }^{1}$ Department of Internal Medicine, Seoul National University Bundang Hospital, Seongnam, ${ }^{2}$ Department of Internal Medicine, Seoul \\ National University College of Medicine, Seoul, ${ }^{3}$ Department of Surgery, Seoul National University Bundang Hospital, Seongnam, and \\ ${ }^{4}$ Department of Surgery, Seoul National University College of Medicine, Seoul, Korea
}

\section{Article Info}

Received May 6, 2021

Revised June 10, 2021

Accepted June 23, 2021

Published online September 1, 2021

\section{Corresponding Author}

\section{Nayoung Kim}

ORCID https://orcid.org/0000-0002-9397-0406

E-mail nakim49@snu.ac.kr

\section{Hyung Ho Kim}

ORCID https://orcid.org/0000-0002-8916-0048

E-mail hhkim@snubh.org

\begin{abstract}
Background/Aims: Less invasive surgical treatment is performed in East Asia to preserve postoperative digestive function and reduce complications such as postgastrectomy syndromes, but there is an issue of metachronous gastric cancer (GC) in the remaining stomach. This study aimed to analyze the incidence of metachronous GC and its risk factors in patients who had undergone partial gastrectomy.

Methods: A total of 3,045 GC patients who had undergone curative gastric partial resection at Seoul National University Bundang Hospital were enrolled and analyzed retrospectively for risk factors, including age, sex, smoking, alcohol, Helicobacter pylori status, family history of GC, histological type, and surgical method.

Results: Metachronous GC in the remaining stomach occurred in 35 of the 3,045 patients $(1.1 \%): 23$ in the distal gastrectomy group (18 with Billroth-I anastomosis, five with Billroth-II anastomosis), seven in the proximal gastrectomy (PG) group, and five in the pylorus-preserving gastrectomy (PPG) group. Univariate and multivariate Cox regression analyses showed that age $\geq 60$ years $(p=0.005)$ and surgical method used (PG or PPG, $p<0.001)$ were related risk factors for metachronous GC, while male sex and intestinal type histology were potential risk factors.

Conclusions: Metachronous GC was shown to be related to older age and the surgical method used (PG or PPG). Regular and careful follow-up with endoscopy should be performed in the case of gastric partial resection, especially in patients with male sex and intestinal type histology as well as those aged $\geq 60$ years undergoing the PG or PPG surgical method. (Gut Liver 2022;16:366-374)
\end{abstract}

Key Words: Stomach neoplasms; Epidemiology; Gastrectomy; Neoplasms, second primary

\section{INTRODUCTION}

Gastric cancer (GC) is common in East Asia, and South Korea's incidence of GC is still the highest in the world although the survival rate is improving significantly, as early diagnosis increases due to the national screening project for GC and the endoscopic and surgical treatment techniques for GC has improved. ${ }^{1,2}$ The standard gastrectomy procedures for GC are distal gastrectomy (DG) and total gastrectomy, and less invasive surgical treatment has been performed in East Asia to preserve postoperative digestive function and reduce complications such as postgastrectomy syndromes. ${ }^{3-7}$ Various procedures are being attempted, including proximal gastrectomy (PG), pylorus-preserving gastrectomy (PPG), and function-preserving gastrectomy. ${ }^{8,9}$ As there is remaining stomach after operation, a possibility of metachronous GC exists. The incidence rate of metachronous GC may be higher than that of primary GC, since the gastric mucosa of patients with a history of GC is thought to have tumor microenvironment conditions such as genetic predisposition and damage caused by the gastric environment, relative to the gastric mucosa of people with- 
out history of GC. ${ }^{10,11}$ Therefore, careful follow-up of the remnant stomach after surgery is required. However, there have been few reports of the incidence or distribution of this type of GC after gastrectomy, none in Korea so far. We hypothesized that there are risk factors for the metachronous GC. From this background, the aim of this study was to analyze the incidence of this type of GC and its risk factors in patients who underwent gastrectomy.

\section{MATERIALS AND METHODS}

\section{Patients}

From May 2003 to January 2018, 3,707 patients' data were collected who were diagnosed with GC and surgically treated at Seoul National University Bundang Hospital (SNUBH). Among them, 3,045 patients who underwent curative gastric partial resection were enrolled. Those who underwent total gastrectomy, palliative debulking surgery, who were finally diagnosed with other cancer than gastric adenocarcinoma, or who were lost to follow-up were excluded (Fig. 1). Two thousand eight hundred one patients received DG, 146 patients received PG, and 98 patients received PPG or segmental gastric resection (Fig. 1). The medical records of these patients were collected using Clinical Data Warehouse of SNUBH and electronic medical record, including age, sex, smoking, alcohol, Helicobacter pylori (HP) status, presence of intestinal metaplasia, family history of GC, histological types, and surgical method.

\section{Follow-up and HP eradication therapy}

We defined metachronous GC as a newly diagnosed cancer that occurred in areas unrelated to surgery, at least 1 year after the surgery during the follow-up period to distinguish it from simultaneous GC (cancer found within 1 year of surgery) and recurrence (cancer associated with prior surgery, such as anastomosis or peritoneal metastasis), referring to previous studies. ${ }^{12-14}$ Scheduled endoscopic follow-ups were conducted for 5 years, with 6 months interval for the first year and with 1 year interval for the next 4 years, and the diagnosis was made by histologic confirmation after operation. There was no difference in followup depending on the surgical methods used.

Atrophic gastritis and intestinal metaplasia were regarded as positive if they were identified in the endoscopic biopsy specimens of mucosa of the antrum or body and considered as negative if such findings did not exist on the specimens. In most patients, atrophic gastritis and intestinal metaplasia were confirmed through endoscopic biopsy samples performed just before surgery, and in patients without preoperative biopsy, biopsy samples performed at the first follow-up within 6 months of surgery were used.

HP-positive subjects were treated with initial eradication therapy, which consisted of triple therapy before 2012 and 10-day sequential therapy was frequently performed since $2012,{ }^{15}$ as our team found the rapid decrease of eradication rate of triple therapy with an increase of resistance of clarithromycin. ${ }^{16}$ The triple therapy regimens consisted of a combination of a standard dose of esomeprazole 40 $\mathrm{mg}$ twice per day, amoxicillin $1 \mathrm{~g}$ twice per day, and clar-

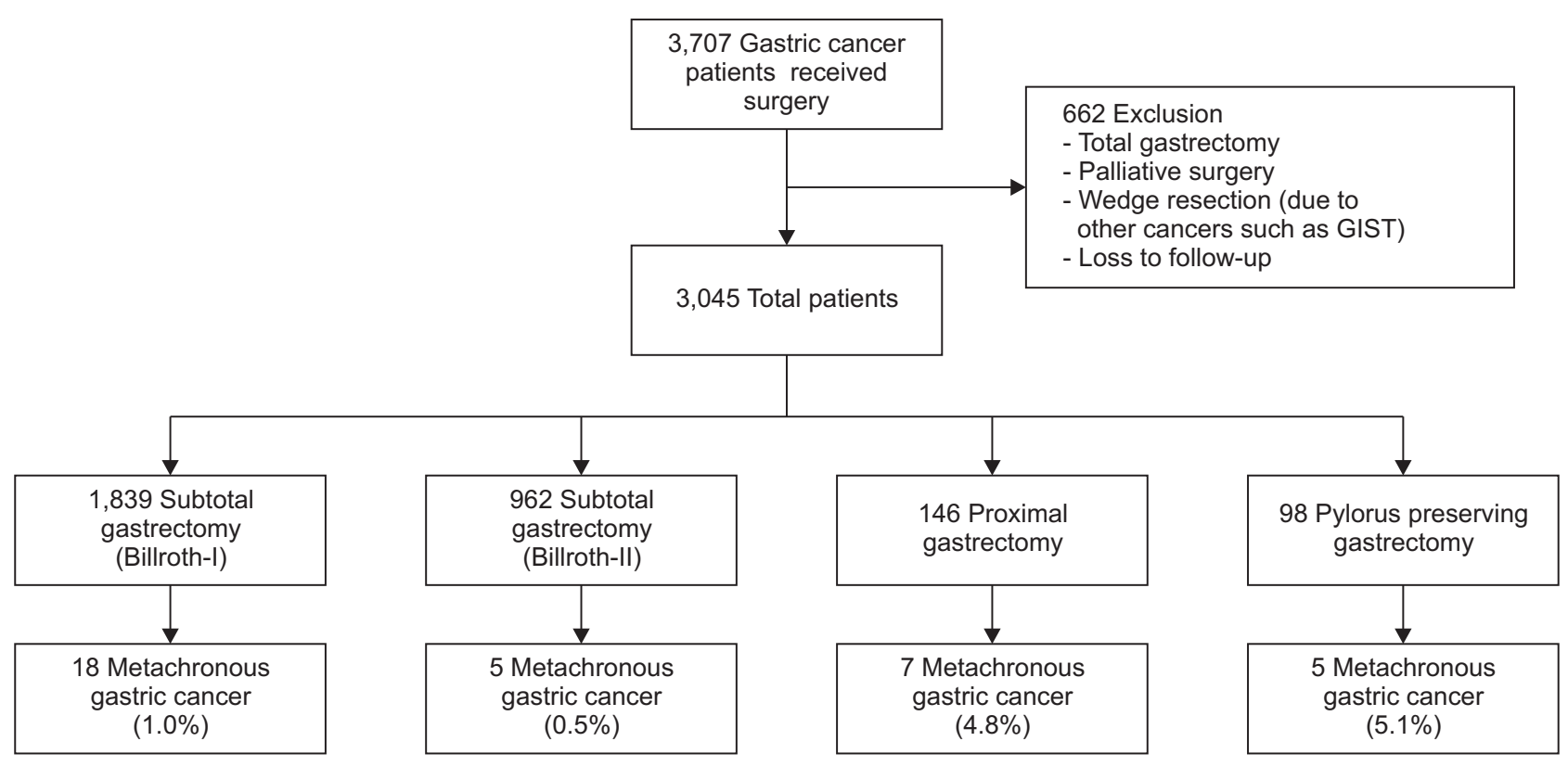

Fig. 1. Study flowchart.

GIST, gastrointestinal stromal tumor. 
ithromycin $500 \mathrm{mg}$ twice per day for 1 week. The 10-day sequential therapy included esomeprazole $40 \mathrm{mg}$, amoxicillin 1,000 mg twice per day for 5 days followed by esomeprazole $40 \mathrm{mg}$, clarithromycin $500 \mathrm{mg}$ and metronidazole $500 \mathrm{mg}$ twice per day for the next 5 days. The assessment of $\mathrm{HP}$ eradication was performed by a ${ }^{13} \mathrm{C}$-urea breath test (UBiTkit; Otsuka Pharmaceutical Co., Ltd., Tokyo, Japan) 4 weeks after the eradication therapy (if there was a possibility of false-positive then follow-up gastroscopic biopsy was performed again) or by histology (Giemsa stain) and rapid urease test when the follow-up gastroscopy was scheduled soon. The patients chose another eradication therapy if the first-line regimen failed: either a 14-day quadruple regimen containing bismuth (esomeprazole $40 \mathrm{mg}$ twice per day, tripotassium dicitrate bismuthate (Denol; Green Cross Corp., Yongin, Korea) $300 \mathrm{mg}$ four times per day, metronidazole $500 \mathrm{mg}$ three times per day and tetracycline $500 \mathrm{mg}$ four times per day) or a 14-day moxifloxacin-based triple therapy (moxifloxacin [Avelox; Bayer AG, Leverkusen, Germany] $400 \mathrm{mg}$ daily, esomeprazole $40 \mathrm{mg}$ twice per day, and amoxicillin $1 \mathrm{~g}$ twice per day). ${ }^{17}$

\section{Consent and institutional review board}

All patients provided written informed consent to participate in this study. The study was performed in accordance with the 53rd World Medical Association Declaration of Helsinki. The study was reviewed and approved by the Institutional Review Board (IRB) of SNUBH (IRB number: B-1902-523-107), and this study protocol has been registered at ClinicalTrials.gov (NCT 03978481).

\section{Statistical analysis}

Statistical analyses were performed using the Student ttest, the Pearson chi-square test, analysis of variance, Cox univariate and multivariate regression model via SPSS for Windows version 25.0 (IBM Corp., Armonk, NY, USA) program.

Table 1. Baseline Characteristics

\begin{tabular}{|c|c|c|c|}
\hline Variable & $\begin{array}{l}\text { Patients with metachronous GC } \\
\qquad(\mathrm{n}=35)\end{array}$ & $\begin{array}{l}\text { Patients without metachronous GC } \\
\qquad(n=3,010)\end{array}$ & $\mathrm{p}$-value \\
\hline Sex & & & 0.100 \\
\hline Female & 7 & 998 & \\
\hline Male & 28 & 2,012 & \\
\hline Age, mean $\pm S D, y r$ & $66.09 \pm 7.58$ & $60.10 \pm 12.38$ & $<0.001^{*}$ \\
\hline Family history of GC & & & 0.918 \\
\hline No & 29 & 2,514 & \\
\hline Yes & 6 & 496 & \\
\hline Smoking status & & & 0.253 \\
\hline No & 16 & 1,668 & \\
\hline Yes & 19 & 1,342 & \\
\hline Alcohol drinking & & & 0.960 \\
\hline No & 19 & 1,648 & \\
\hline Yes & 16 & 1,362 & \\
\hline Gastric atrophy & & & $0.026^{*}$ \\
\hline Absent & 21 & 2,293 & \\
\hline Present & 14 & 717 & \\
\hline Intestinal metaplasia & & & $0.002 *$ \\
\hline Absent & 13 & 1,879 & \\
\hline Present & 22 & 1,131 & \\
\hline Histologic type (Lauren's classification) & & & $0.008^{*}$ \\
\hline Intestinal & 28 & 1,650 & \\
\hline Diffuse & 5 & 1,190 & \\
\hline Mixed or undifferentiated & 2 & 170 & \\
\hline Helicobacter pyloristatus & & & 0.368 \\
\hline Eradicated & 10 & 771 & \\
\hline Negative & 20 & 1,408 & \\
\hline Positive (not treated) & 5 & 831 & \\
\hline Surgical method for initial GC & & & $<0.001 *$ \\
\hline Billroth-I & 18 & 1,821 & \\
\hline Billroth-II & 5 & 957 & \\
\hline Proximal gastrectomy & 7 & 139 & \\
\hline Pylorus-preserving gastrectomy & 5 & 93 & \\
\hline
\end{tabular}

GC, gastric cancer.

*Statistically significant, $p<0.05$. 


\section{RESULTS}

\section{Incidence and clinicopathological characteristics of patients with metachronous GC}

Of the 3,045 patients analyzed, metachronous GC occurred in 35 patients (1.1\%). According to surgical method they were found to be 23 in the DG group (18 with BillrothI anastomosis and five with Billroth-II anastomosis), seven in the PG group, and five in the PPG group (Fig. 1). Baseline characteristics of the patients are shown in Table 1. There were differences in the mean age, presence of intestinal metaplasia, histologic type and surgical methods used between patients with and without metachronous gastric neoplasm (MGN). The number of metachronous cancer patients according to the stage of primary cancer at the time of surgery was as follows: IA 25/1,773 (1.4\%), IB
4/448 (0.9\%), IIA 4/309 (1.3\%), and IIB 2/175 (1.1\%). Statistical significance was not observed $(\mathrm{p}=0.998$ using the Cox regression analysis).

The time interval from initial cancer surgery to diagnosis of metachronous GC was median 50 months, maximum 156 months. The average time interval according to the surgical methods used was as follows: 63 months in Billroth-I group, 46 months in Billroth-II group, 55 months in PG group, and 48 months in PPG group. Statistical significance was not confirmed since the number of each group was too small.

\section{Risk factors of metachronous GC}

Multiple variables including sex, age, family history of GC, history of smoking and alcohol drinking, presence of gastric atrophy or intestinal metaplasia, histologic type of

Table 2. Risk Factors for Metachronous Gastric Cancer

\begin{tabular}{|c|c|c|c|c|}
\hline \multirow{2}{*}{ Variable } & \multicolumn{2}{|c|}{ Univariate analysis } & \multicolumn{2}{|c|}{ Multivariate analysis } \\
\hline & aHR (95\% CI) & $p$-value & aHR (95\% CI) & $p$-value \\
\hline Sex & & $0.048^{*}$ & & 0.266 \\
\hline Female & Reference & & Reference & \\
\hline Male & $2.30(1.01-5.29)$ & & $1.62(0.69-3.81)$ & \\
\hline Age & & $0.002^{*}$ & & $0.018^{*}$ \\
\hline$<60 \mathrm{yr}$ & Reference & & Reference & \\
\hline$\geq 60 \mathrm{yr}$ & $3.74(1.63-8.56)$ & & $2.78(1.19-6.49)$ & \\
\hline Family history of GC & & 0.975 & & \\
\hline No & Reference & & & \\
\hline Yes & 0.99 (0.41-2.38) & & & \\
\hline Smoking status & & 0.156 & & \\
\hline No & Reference & & & \\
\hline Yes & $1.62(0.83-3.15)$ & & & \\
\hline Alcohol drinking & & 0.992 & & \\
\hline No & Reference & & & \\
\hline Yes & $1.00(0.51-1.94)$ & & & \\
\hline Gastric atrophy & & 0.129 & & \\
\hline Absent & Reference & & & \\
\hline Present & $1.69(0.86-3.33)$ & & & \\
\hline Intestinal metaplasia & & $0.011^{*}$ & & 0.133 \\
\hline Absent & Reference & & Reference & \\
\hline Present & $2.43(1.23-4.84)$ & & $1.71(0.85-3.46)$ & \\
\hline Histologic type (Lauren's classification) & & $0.014^{*}$ & & 0.189 \\
\hline Intestinal & Reference & & Reference & \\
\hline Diffuse & $0.24(0.09-0.63)$ & & $0.40(0.15-1.08)$ & \\
\hline Mixed or undifferentiated & $0.66(0.16-2.80)$ & & $0.77(0.18-3.35)$ & \\
\hline Helicobacter pylori & & 0.087 & & 0.429 \\
\hline Eradicated & Reference & & Reference & \\
\hline Negative & $2.18(1.00-4.75)$ & & $1.69(0.75-3.82)$ & \\
\hline Positive (not treated) & $1.02(0.34-3.02)$ & & $1.19(0.39-3.60)$ & \\
\hline Surgical method for initial GC & & $<0.001 *$ & & $<0.001^{*}$ \\
\hline Billroth-I & Reference & & Reference & \\
\hline Billroth-II & $0.65(0.29-2.16)$ & & $0.84(0.31-2.29)$ & \\
\hline Proximal gastrectomy & $7.60(3.10-18.61)$ & & $6.71(2.66-16.94)$ & \\
\hline Pylorus-preserving gastrectomy & $10.27(3.66-28.81)$ & & $8.93(3.12-25.54)$ & \\
\hline
\end{tabular}

aHR, adjusted hazard ratio; $\mathrm{Cl}$, confidence interval; $\mathrm{GC}$, gastric cancer.

*Statistically significant, $p<0.05$. 
initial GC, HP status, and surgical methods used were analyzed using the Cox regression analyses, and the results are shown in Table 2. In the Cox univariate analysis, male sex (adjusted hazard ratio [aHR], 2.30; $\mathrm{p}=0.048$ ), age $\geq 60$ years (aHR, 3.74; $<<0.001)$, presence of intestinal metaplasia (aHR, 2.43; $\mathrm{p}=0.011)$, intestinal type histology $(\mathrm{p}=0.014)$, and surgical methods used (aHR of PG, 7.60; aHR of PPG, 10.27; $\mathrm{p}<0.001$ ) were potential risk factors, and the Cox multivariate analysis revealed only age $\geq 60$ years (aHR, 2.78; $\mathrm{p}=0.018$ ) and surgical methods used ( $\mathrm{aHR}$ of $\mathrm{PG}, 6.71$; aHR of PPG, 8.93; $\mathrm{p}<0.001$ ) were independent risk factors for metachronous GC (Table 2). In terms of the correlation between metachronous GC and HP, 10 out of 35 patients received postoperative HP eradication treatment after initial surgery, 20 patients were negative for HP, and five patients were HP positive at the time of metachronous cancer occurrence (they did not receive eradication treatment). Although the incidence of metachronous GC in HP negative patients was somewhat high in the Cox univariate analysis (aHR, 2.18; $\mathrm{p}=0.087$ ), multivariate analysis did not confirm a statistical significance.

We did additional analyses targeting patients who underwent DG, since DG procedure is the most common procedure, and the characteristics of the cancer can vary depending on the location of the tumor. The results are demonstrated in Supplementary Table 1. In the Cox univariate analysis, age $\geq 60$ years ( $a H R, 3.30 ; p=0.019$ ) was a potential risk factor. However, statistical significance was not seen in the Cox multivariate analysis since the number of metachronous GC cases had decreased.

\section{Clinicopathological characteristics of patients with metachronous GC}

Clinicopathological characteristics of metachronous GC are demonstrated in Table 3 . Thirty cases of metachronous GC were early GCs and five cases were advanced GCs. The location of initial GC was as follows: cardia (three cases), fundus (one case), body (16 cases), and antrum (15 cases). Most of them (33/35 cases, 94\%) were completely curable, as they were treated with endoscopic resection (10 cases) and remnant total gastrectomy (23 cases). Among them, two patients underwent additional surgery after incomplete endoscopic resection for metachronous lesion. Only two patients were treated with systemic chemotherapy, who were unable to receive curative resection because of disease progression or other comorbidities (Table 3).

The histologic types of metachronous GCs were as follows: intestinal type (23 cases), diffuse type (six cases), and mixed type (one case). In five patients, histologic types could not be identified due to non-operational or omission of biopsy results. Statistical significance was not observed between the tumor location and the histologic type of metachronous cancer ( $\mathrm{p}=0.269$ using the bivariate correlation analysis).

Table 3. Clinicopathological Characteristics of Patients with Metachronous Gastric Cancer

\begin{tabular}{|c|c|}
\hline Patients with metachronous GC ( $n=35$ ) & No. $(\%)$ \\
\hline \multicolumn{2}{|l|}{ Type of metachronous GC } \\
\hline Early GC & $30(85.7)$ \\
\hline Advanced GC & 5 (14.3) \\
\hline \multicolumn{2}{|l|}{ Surgical method for initial GC } \\
\hline Billroth-I & 18 (51.4) \\
\hline Billroth-II & 5 (14.3) \\
\hline Proximal gastrectomy & $7(20.0)$ \\
\hline Pylorus-preserving or segmental gastrectomy & $5(14.3)$ \\
\hline \multicolumn{2}{|l|}{ Treatment modality for metachronous GC } \\
\hline Endoscopic resection (EMR or ESD) & $10(28.6)$ \\
\hline Surgical resection after endoscopic resection & $2(5.7)$ \\
\hline Surgical resection (remnant total gastrectomy) & $21(60.0)$ \\
\hline Chemotherapy & $2(5.7)$ \\
\hline \multicolumn{2}{|l|}{ Helicobacter pylori status at time of metachronous GC diagnosis } \\
\hline Eradicated (after initial GC surgery) & $10(28.6)$ \\
\hline Negative (persistently negative) & $20(57.1)$ \\
\hline Positive & $5(14.3)$ \\
\hline \multicolumn{2}{|l|}{ Location of initial GC } \\
\hline Cardia & $3(8.6)$ \\
\hline Fundus & $1(2.9)$ \\
\hline Body & $16(45.7)$ \\
\hline Antrum & 15 (42.9) \\
\hline
\end{tabular}

GC, gastric cancer; EMR, endoscopic mucosal resection; ESD, endoscopic submucosal dissection. 


\section{DISCUSSION}

In this study, the overall incidence of metachronous GC was $1.1 \%$, and the incidence was much higher in PG and PPG groups. The Cox univariate and multivariate analyses revealed that age $\geq 60$ years and surgical methods used (PG or PPG) were independent risk factors, while male sex and intestinal type histology would be potential risk factors. This is the first report regarding metachronous GC after surgery for GC in Korea, so far.

It is ideal to minimize the resected range as possible, and gastric partial resection is a useful treatment option because it has the advantage of preserving reservoir, digestive function, body weight and reducing postoperative complications such as postgastrectomy syndrome, gallstones and anemias, with similar cancer recurrence and postoperative mortality, although there is risk of metachronous GC in the remaining stomach. ${ }^{9,18,19}$ The incidence and related risk factors of metachronous GC, and time from initial gastrectomy to metachronous GC diagnosis have been unclear yet. ${ }^{10,11,20,21}$

Reviewing the results of previous studies about metachronous GC after partial gastric resection, the incidence of metachronous GC varies wide, as $1 \%$ to $2 \%$ after $\mathrm{DG}^{22-27}$ and $6 \%$ to $10 \%$ after PG or PPG. ${ }^{13,28,29}$ In the recently published nationwide study in Japan, the precise incidence of metachronous GC was estimated to be $2.35 \%$ after DG, 3.01\% after PPG, 6.28\% after PG and 8.21\% after functionpreserving gastrectomy, respectively. ${ }^{30}$ In our data, the incidence was $0.8 \%$ after DG, $4.7 \%$ after PG and $4.1 \%$ after PPG, higher in patients who received PG or PPG with statistical significance. The lower prevalence of metachronous GC in this study is believed to be due to that only GC occurred in areas unrelated to anastomosis site after at least 1 year of surgery, since there is a possibility of simultaneous cancer which have been missed at the time of diagnosis in the case of GC found within a year after surgical resection of initial cancer. ${ }^{14,31-33}$ Also, regular endoscopic followup with radical resection of precancerous lesions such as gastric adenoma was performed in our hospital. ${ }^{33}$ In this report, MGN developed in $7.4 \%$ in the 257 patients with gastric neoplasm (113 low-grade dysplasias, 25 high-grade dysplasias, and 119 early GCs) during a mean follow-up of 52 months. ${ }^{34}$ Multivariate analysis showed that moderate/ severe corpus intestinal metaplasia and family history of GC were independent risk factors for MGN development; the hazard ratios were 4.12 (95\% confidence interval, 1.23 to $13.87 ; \mathrm{p}=0.022$ ) and 3.52 (95\% confidence interval, 1.09 to $11.40 ; \mathrm{p}=0.036$ ), respectively. The methylation level of $M O S$ in the CpG sites which as correlated with severity of intestinal metaplasia ${ }^{35,36}$ was significantly elevated in pa- tients with MGN compared age- and sex-matched patients without MGN ( $\mathrm{p}=0.020)$. In another similar study regarding risk of MGN occurrence after endoscopic submucosal dissection for gastric dysplasia showed that MGNs developed in 21 patients (10.6\%) in the low-grade dysplasia group and in six patients (13.0\%) in the high-grade dysplasia group. ${ }^{37}$ In the present study the overall incidence of metachronous GC was $1.1 \%$, which is lower rate of MGN after endoscopic treatment. It could be a meaningful result that a higher incidence rate of metachronous GC was observed in patients with PG or PPG compared to patients with DG.

Previously known risk factors for metachronous GC were male sex, ${ }^{21,28,29} \mathrm{PG},{ }^{13,28}$ older age, invasion of submucosal layer, ${ }^{13}$ intestinal type histology, ${ }^{21}$ and macroscopic type (O-IIa). ${ }^{29}$ In this study, male sex, older age, presence of intestinal metaplasia, intestinal type histology and surgical methods (PG or PPG) were potential risk factors. In addition, multivariate analyses revealed that older age and surgical methods (PG or PPG) as risk factors for metachronous GC, respectively. Previous studies have suggested possibilities for high incidence of MGN after PG or PPG. There might be several reasons for this result. First, the area of the gastric mucosa left after PG is much wider, as one-fifth to one-third of the proximal stomach is preserved with the DG or the PPG, ${ }^{38}$ while one-half to two-thirds of the distal stomach is preserved with the PG. ${ }^{39}$ Second, the antrum has a higher rate of GC than the body, with the possibility that the lower third of the stomach has more foci of multicentric carcinogenesis than the upper third of the stomach. ${ }^{13,40}$ Third, the reduction of bile reflux and the increased effects of HP infection after PG or PPG could be the reason. ${ }^{28}$ It is well known that eradication of HP is needed to prevent metachronous GC after endoscopic resection of early $\mathrm{GC}^{41}$ but it is not yet clear about HP eradication and metachronous GC incidence after gastrectomy, with no statistically significant connection has been reported so far. Further research is needed considering that HP contributes to stomach cancer. Another explanation could be hypergastrinemia which plays a role in the occurrence of metachronous GC. G cells that secret gastrin are distributed in the antrum. ${ }^{28,42-44}$ In addition to these, another reason might be that thorough examination of remnant stomach and resection of lesion are more difficult in patients after PG, especially in cases with long efferent loop. In several studies, male sex has been reported as a risk factor for metachronous GC, and although no precise mechanism is known, intestinal type histology is believed to be associated with this. ${ }^{21}$ In our data, although not statistically significant, male sex and intestinal type histology have been shown to be potential risk factors for metachronous GC. 
This study has several limitations. First, this was a retrospective study and the number of patients with metachronous GC were small as it was conducted by a single institution, although over 3,000 patients from more than 15 years of study period were enrolled. Multicenter trial with a larger number of metachronous GC patients including the influence of other risk factors such as HP would be needed. Second, study with longer period is needed, since metachronous GC can still occur 10 years after surgery. ${ }^{13,21}$ However, there were cases that occurred more than 12 years after initial surgery in our data. Third, not only the occurrence of metachronous cancer but also the occurrence of dysplasia, a precursor to cancer, is clinically important. Unfortunately, we could not analyze data for gastric adenoma cases in this study since it was very difficult to find out the metachronous adenoma cases from Clinical Data Warehouse mainly because it was hidden under the diagnosis of GC category, and the total number of patients are approximately 3,700 . Instead, we reviewed the previous reports. There were no studies of the incidence of MGNs including adenoma after partial gastrectomy so far, and most of the literature deals only with the cancer. However, several reports analyzed MGN including adenoma after endoscopic therapy for the GC. Previously, we report that the incidence of metachronous neoplasm after endoscopic resection (endoscopic mucosal resection or endoscopic submucosal dissection) was 7.4\% (19/259; 12 adenomas and seven adenocarcinomas) $)^{34}$ and $16.1 \%$ (13 adenomas and seven adenocarcinomas), in a subsequent study being performed. Referring to other studies reported in Korea, the number of metachronous adenomas and cancers after DG was 18 and 12 (however, in this study, the incidence of metachronous neoplasms could not be identified since only cases treated with endoscopic submucosal dissection were collected). ${ }^{45}$ And Kim et al. ${ }^{37}$ reported that the incidence of metachronous neoplasms after endoscopic treatment for gastric dysplasia was $11.0 \%$, and the number of metachronous adenomas and cancers was 24 (18 lowgrade adenomas and six high-grade adenomas) and three, respectively. Although the number of MGNs in patients received surgery might be smaller due to the decreased area of the remnant stomach after surgery, the ratio of adenoma and cancer could be similar. Later, it will need to be analyzed through a follow-up study that includes both adenoma and cancer. Finally, HP was diagnosed and identified through repeated endoscopic biopsy in most subjects. However, due to practical difficulties such as patients who were not possible to undergo endoscopy again, histologic tests such as Giemsa stain for HP were not performed.

In conclusion, metachronous GC was diagnosed in 1.1\% of patients who underwent partial gastric resection and was related to older age and surgical methods used (PG or PPG). Male sex and intestinal type histology were potential risk factors for metachronous GC. Regular and careful follow-up with endoscopy should be premised in the case of gastric partial resection, especially in patients accompanied by these risk factors.

\section{CONFLICTS OF INTEREST}

No potential conflict of interest relevant to this article was reported.

\section{ACKNOWLEDGEMENTS}

This work was supported by another grant (number: 13-2019-001) from the Seoul National University Bundang Hospital Research Fund.

\section{AUTHOR CONTRIBUTIONS}

Conceptualization: N.K., H.H.K. Data curation: Y.C., H.H.K. Formal analysis: Y.C., N.K. Funding acquisition: N.K. Methodology: Y.S.P., S.H.A., Y.S.S., D.J.P., H.H.K. Project administration: N.K., H.H.K. Visualization: H.Y., C.M.S., Y.S.P., D.H.L. Writing - original draft: Y.C. Writing - review \& editing: N.K., H.Y., C.M.S., Y.S.P., D.H.L. Approval of final manuscript: all authors.

\section{ORCID}

Yonghoon Choi https://orcid.org/0000-0002-1331-969X Nayoung Kim https://orcid.org/0000-0002-9397-0406 Hyuk Yoon https://orcid.org/0000-0002-2657-0349 Cheol Min Shin https://orcid.org/0000-0003-2265-9845 Young Soo Park https://orcid.org/0000-0003-1893-7726 Dong Ho Lee https://orcid.org/0000-0002-6376-410X Young Suk Park https://orcid.org/0000-0002-6352-9759 Sang-Hoon Ahn https://orcid.org/0000-0001-8827-3625 Yun-Suhk Suh https://orcid.org/0000-0003-3319-8482 Do Joong Park https://orcid.org/0000-0001-9644-6127 Hyung Ho Kim https://orcid.org/0000-0002-8916-0048

\section{SUPPLEMENTARY MATERIALS}

Supplementary materials can be accessed at https://doi. org/10.5009/gnl210202. 


\section{REFERENCES}

1. Ferlay J, Soerjomataram I, Dikshit R, et al. Cancer incidence and mortality worldwide: sources, methods and major patterns in GLOBOCAN 2012. Int J Cancer 2015;136:E359E386.

2. Jun JK, Choi KS, Lee HY, et al. Effectiveness of the Korean National Cancer Screening Program in reducing gastric cancer mortality. Gastroenterology 2017;152:1319-1328.

3. Nakada K, Ikeda M, Takahashi M, et al. Characteristics and clinical relevance of Postgastrectomy Syndrome Assessment Scale (PGSAS)-45: newly developed integrated questionnaires for assessment of living status and quality of life in postgastrectomy patients. Gastric Cancer 2015;18:147-158.

4. Terashima M, Tanabe K, Yoshida M, et al. Postgastrectomy Syndrome Assessment Scale (PGSAS)-45 and changes in body weight are useful tools for evaluation of reconstruction methods following distal gastrectomy. Ann Surg Oncol 2014;21 Suppl 3:S370-S378.

5. Nakada K, Takahashi M, Ikeda M, et al. Factors affecting the quality of life of patients after gastrectomy as assessed using the newly developed PGSAS-45 scale: a nationwide multiinstitutional study. World J Gastroenterol 2016;22:89788990.

6. Kinami S, Takahashi M, Urushihara T, et al. Background factors influencing postgastrectomy syndromes after various types of gastrectomy. World J Clin Cases 2018;6:1111-1120.

7. Japanese Gastric Cancer Association. Japanese gastric cancer treatment guidelines 2018 (5th edition). Gastric Cancer 2021;24:1-21.

8. Fujimura T, Fushida S, Kayahara M, Ohta T, Kinami S, Miwa K. Transectional gastrectomy: an old but renewed concept for early gastric cancer. Surg Today 2010;40:398-403.

9. Kinami S, Funaki H, Fujita H, Nakano Y, Ueda N, Kosaka T. Local resection of the stomach for gastric cancer. Surg Today 2017;47:651-659.

10. Kaibara N, Ikeguchi M. Carcinogenetic risk and gastric surgery-metachronous gastric cancer after distal gastrectomy. In: Sowa M, Miwa K, eds. Carcinoma of the remnant stomach; the sequel. Osaka: Iyaku-Journal Coop, 2000:137-142.

11. Kinami S, Miwa K. Prevention of the remnant gastric cancer. In: Sowa M, Miwa K, eds. Carcinoma of the remnant stomach; the sequel. Osaka: Iyaku-Journal Coop, 2000:262-272.

12. Kim HJ, Kim YJ, Seo SI, Shin WG, Park CH. Impact of the timing of Helicobacter pylori eradication on the risk of development of metachronous lesions after treatment of early gastric cancer: a population-based cohort study. Gastrointest Endosc 2020;92:613-622.

13. Nozaki I, Nasu J, Kubo Y, Tanada M, Nishimura R, Kurita A. Risk factors for metachronous gastric cancer in the remnant stomach after early cancer surgery. World J Surg

\section{0;34:1548-1554.}

14. Nozaki I, Hato S, Kobatake T, et al. Incidence of metachronous gastric cancer in the remnant stomach after synchronous multiple cancer surgery. Gastric Cancer 2014;17:61-66.

15. Choi Y, Kim N, Yun CY, et al. Effect of Helicobacter pylori eradication after subtotal gastrectomy on the survival rate of patients with gastric cancer: follow-up for up to 15 years. Gastric Cancer 2020;23:1051-1063.

16. Lee JY, Kim N, Kim MS, et al. Factors affecting first-line triple therapy of Helicobacter pylori including CYP2C19 genotype and antibiotic resistance. Dig Dis Sci 2014;59:12351243.

17. Yoon K, Kim N, Nam RH, et al. Ultimate eradication rate of Helicobacter pylori after first, second, or third-line therapy in Korea. J Gastroenterol Hepatol 2015;30:490-495.

18. Nozaki I, Hato S, Kobatake T, Ohta K, Kubo Y, Kurita A. Long-term outcome after proximal gastrectomy with jejunal interposition for gastric cancer compared with total gastrectomy. World J Surg 2013;37:558-564.

19. Suh YS, Han DS, Kong SH, et al. Laparoscopy-assisted pylorus-preserving gastrectomy is better than laparoscopyassisted distal gastrectomy for middle-third early gastric cancer. Ann Surg 2014;259:485-493.

20. Ohashi M, Katai H, Fukagawa T, Gotoda T, Sano T, Sasako M. Cancer of the gastric stump following distal gastrectomy for cancer. Br J Surg 2007;94:92-95.

21. Morgagni P, Gardini A, Marrelli D, et al. Gastric stump carcinoma after distal subtotal gastrectomy for early gastric cancer: experience of 541 patients with long-term follow-up. Am J Surg 2015;209:1063-1068.

22. Kosaka T, Miwa K, Yonemura Y, et al. A clinicopathologic study on multiple gastric cancers with special reference to distal gastrectomy. Cancer 1990;65:2602-2605.

23. Moreaux J, Mathey P, Msika S. Gastric adenocarcinoma in the gastric stump after partial gastrectomy. Hepatogastroenterology 1991;38:517-521.

24. Ojima T, Iwahashi M, Nakamori M, et al. Clinicopathological characteristics of remnant gastric cancer after a distal gastrectomy. J Gastrointest Surg 2010;14:277-281.

25. Komatsu S, Ichikawa D, Okamoto K, et al. Progression of remnant gastric cancer is associated with duration of followup following distal gastrectomy. World J Gastroenterol 2012;18:2832-2836.

26. Takeno S, Noguchi T, Kimura Y, Fujiwara S, Kubo N, Kawahara K. Early and late gastric cancer arising in the remnant stomach after distal gastrectomy. Eur J Surg Oncol 2006;32:1191-1194.

27. Ahn HS, Kim JW, Yoo MW, et al. Clinicopathological features and surgical outcomes of patients with remnant gastric cancer after a distal gastrectomy. Ann Surg Oncol 2008;15:1632-1639. 
28. Iwata $\mathrm{Y}$, Ito S, Misawa K, et al. Incidence and treatment of metachronous gastric cancer after proximal gastrectomy. Surg Today 2018;48:552-557.

29. Aizawa M, Yabusaki H, Matsuki A, Bamba T, Nakagawa S. Incidence of multiple metachronous gastric cancers after pyloric-preserving gastrectomy. World J Surg 2020;44:27192727.

30. Kinami S, Aizawa M, Yamashita H, et al. The incidences of metachronous multiple gastric cancer after various types of gastrectomy: analysis of data from a nationwide Japanese survey. Gastric Cancer 2021;24:22-30.

31. Ohtani H, Yashiro M, Onoda N, et al. Synchronous multiple primary gastrointestinal cancer exhibits frequent microsatellite instability. Int J Cancer 2000;86:678-683.

32. Kang GH, Kim CJ, Kim WH, Kang YK, Kim HO, Kim YI. Genetic evidence for the multicentric origin of synchronous multiple gastric carcinoma. Lab Invest 1997;76:407-417.

33. Miyoshi E, Haruma K, Hiyama T, et al. Microsatellite instability is a genetic marker for the development of multiple gastric cancers. Int J Cancer 2001;95:350-353.

34. Yoon H, Kim N, Shin CM, et al. Risk factors for metachronous gastric neoplasms in patients who underwent endoscopic resection of a gastric neoplasm. Gut Liver 2016;10:228-236.

35. Shin CM, Kim N, Park JH, et al. Prediction of the risk for gastric cancer using candidate methylation markers in the non-neoplastic gastric mucosae. J Pathol 2012;226:654-665.

36. Shin CM, Kim N, Lee HS, et al. Changes in aberrant DNA methylation after Helicobacter pylori eradication: a longterm follow-up study. Int J Cancer 2013;133:2034-2042.

37. Kim YI, Park JY, Kim BJ, Hwang HW, Hong SA, Kim
JG. Risk of metachronous gastric neoplasm occurrence during intermediate-term follow-up period after endoscopic submucosal dissection for gastric dysplasia. Sci Rep 2020;10:6747.

38. Shibata C, Shiiba KI, Funayama Y, et al. Outcomes after pylorus-preserving gastrectomy for early gastric cancer: a prospective multicenter trial. World J Surg 2004;28:857-861.

39. Katai H, Sano T, Fukagawa T, Shinohara H, Sasako M. Prospective study of proximal gastrectomy for early gastric cancer in the upper third of the stomach. Br J Surg 2003;90:850853.

40. Nasu J, Doi T, Endo H, Nishina T, Hirasaki S, Hyodo I. Characteristics of metachronous multiple early gastric cancers after endoscopic mucosal resection. Endoscopy 2005;37:990993.

41. Choi IJ, Kook MC, Kim YI, et al. Helicobacter pylori therapy for the prevention of metachronous gastric cancer. N Engl J Med 2018;378:1085-1095.

42. Waldum HL, Sagatun L, Mjønes P. Gastrin and gastric cancer. Front Endocrinol. 2017;8:1-7.

43. Smith JP, Shih AH, Wotring MG, McLaughlin PJ, Zagon IS. Characterization of CCK-B/gastrin-like receptors in human gastric carcinoma. Int J Oncol 1998;12:411-419.

44. Watson S, Durrant L, Morris D. Gastrin: growth enhancing effects on human gastric and colonic tumour cells. Br J Cancer 1989;59:554-558.

45. Lee JY, Min BH, Lee JG, et al. Endoscopic submucosal dissection for early gastric neoplasia occurring in the remnant stomach after distal gastrectomy. Clin Endosc 2016;49:182186. 